\title{
On the Diversified Practice of Teachers' Roles with the Goal of Stimulating Students' Internal Motivation
}

\author{
Nuo Chen ${ }^{1, \dagger}$, Yuxin Dai ${ }^{2, \dagger}$, Xiaoyan Fan ${ }^{3, \dagger}$, Yixuan Pang ${ }^{4, *}, \dagger$ \\ ${ }^{1}$ School of Languages, Shanghai University of International Business and Economics, Shanghai, China \\ ${ }^{2}$ School of German, Hefei University, Hefei, Anhui, China \\ ${ }^{3}$ School of Music, Soochow University, Suzhou, Jiangsu, China \\ ${ }^{4}$ Faculty of Education, Western University of Ontario, London, Ontario, Canada \\ *Corresponding author Email: ypang56@uwo.ca \\ Those authors contributed equally.
}

\begin{abstract}
Teachers are the core of the school, and it is the foundation of every educational system. Parents worldwide are eager and anxious to find the "Best" teacher for their children. Over time, the concept of the "best teacher is vague. It is often measured from various aspects, such as the learning outcomes and development of autonomous learning skills of the students. However, as students enter post-secondary and higher Education, their expectations from the teachers become more heightened. A single characteristic of the teacher might not be enough to take care of students' needs academically and psychologically. Then, based on literature and case studies in similar areas of the study, this short review article argues that on the diversified practice of teachers' roles to stimulate students' internal motivation. The discussions and findings are based on different theoretical interpretations of teachers' comprehensive multi-role literacy; when teachers face different students with diversified tasks, including the time outside of the classroom, and flexibly change their roles, providing emotional Scaffolding for the students. The essay concludes by highlighting the trade-offs between roles to provide optimal guidance for the students to motivate their internal learning motivation.
\end{abstract}

Keywords: teachers' roles, internal motivation, emotional Scaffolding, Zone of Proximal Development $(Z P D)$, role literacies, student-centered, autonomous learner

\section{PREFACE}

As the world becomes globalized, the orientation of teachers' roles is constantly evolving and changing. Nowadays, teacher-centered, or student-led education is not the only paradigm in the field of education. Instead, a diversified education and teaching environment and comprehensive education integrated from the global context and international education are popularized. Meanwhile, it challenges the perception of binary education. Students' expectations towards teachers will be put forward, and the demands for their diversified roles and functions will become higher, especially in higher education. Based on the previous implementation of education and teaching, and under the new background of education and teaching, the definition, content, and realization of teachers' diversified roles have changed and updated its connotation and expression. The positive proportional relationship between the realization of teachers' diversified roles and students' learning experiences is also the internal motivation of teachers' diversified roles.

\section{THE PRACTICAL AND THEORETICAL BACKGROUND OF THE EXISTENCE OF TEACHERS' DIVERSIFIED ROLES}

Teachers are playing dimensional roles to improve students' understanding of both knowledge and skills. From this perspective, many researches have been done to explain and analyze the interactions and resulting effects. This part includes pragmatism, humanistic, constructivism theoretic reviews.

\subsection{Pragmatism, represented by Dewey, puts forward that teachers should not be information providers but facilitators.}

In 1916, a book named "Democracy and Education" (Dewey, 1997) [1] appeared in America, a systematic 
and pragmatic educational philosophy. At that time, there were two problems in traditional American Education: it was separated from society and children. Given this phenomenon, its author, John Dewey, put forward "Education as a necessity of life. It is the very nature of life too strict to continue in being." [1] As the founder of American pragmatic philosophy, Dewey emphasized learning by doing and paying attention to obtaining direct experience instead of blindly pursuing theoretical knowledge in the book. In addition, he put forward the "new three centers," which are namely children's center, experience center, and activity center. [1]

According to his theories, teachers' roles have some transformations. People who hold these opinions believe students are the center of Education. Therefore, teachers should play the role of facilitator to guide students' learning. The pattern is no longer about the process of how teachers give the lecture and provide information but about how children acquire what they need, including physical and mental support.

In fact, what students learn should be closely related to their future, likewise workplace. With the support of skills, they have trained, they are qualified to address a wide range of affairs. In this way, teachers are not just an information providers but facilitators who give a hand to kids to cultivate their actual abilities to overcome coming problems.

\subsection{Humanistic theory holds that the teacher's duty is not to impart knowledge or learning methods but to provide teaching means for students to learn and promote students' learning.}

Humanism attaches great importance to human beings' values and holds that human beings are the center of all things. Therefore, the purpose of Education is to shape people and make them perfect and developed. As a representative figure of humanism, Carl Ransom Rogers puts forward that training should use cognitive methods and emotional methods to form people who are informed and integrated, that is called, "fully functioning person" (Rogers, 1961) [2]. To achieve this ultimate educational ideal, we should cultivate people who can adapt to changes and guide how to learn.

Taking Rogers' "non-directive" teaching model as an example, its meaning should be less "directness, imperative and directive" and more "non-explicitness, indirection and non-imperative." (Rogers, 1942) [3] This kind of self-evaluation enables students to take responsibility for their studies to learn more actively, effectively, and permanently. On the other hand, the "non-directive" teaching concept puts emphasis on creating a free learning atmosphere, which actually has some drawbacks, to some extent, as it can't guarantee the quality and efficiency of studying.

Apart from Rogers, Abraham H. Maslow is one of the representatives of people-centered theory, who brought up "Intrinsic learning." $\mathrm{He}$ believes that external learning is passive and mechanical learning, relying on reinforcement and conditional functions (Maslow, 1973) [4]. Therefore, ideal universities should oppose external learning and advocate internal learning. In conclusion, internal learning depends on students' internal drive, fully developing their potential, and achieving self-fulfilling learning.

\subsection{Constructivism holds that teachers should be facilitators, collaborators, learners, and explorers.}

In the last century, due to the formation of rigid teaching models (imparting-receiving), people began to criticize and look for a new teaching application concept. At this time, Piaget's theory (which put forward the idea of schema, assimilation, adaptation, and balance) [5] was discovered and attracted many people to study. Kohlberg further studied cognitive structure's nature and development conditions, while Sternberg and Katz explored how to bring the individual initiative into play in the mental process. Meanwhile, Vygotsky found the "Cultural and Historical Development Theory" and put forward the "Zone of Proximal Development". To be more precise, two levels can be reached when studying; one is the level that students themselves can achieve, and the other is the level that students can achieve with the help of others, which is the closest between these two levels [6]. This concept has dramatically developed constructivism.

Through the constructivism teaching concept, the relationship between teachers and students has significantly changed. Teachers are no longer the lecturers of cramming knowledge but the facilitators, collaborators, learners, and explorers. Students should learn new knowledge actively and interactively. Teachers are no longer teaching students directly with their views and existing learning in textbooks, but teaching rooted in students' previous experience and providing scaffolding. Moreover, in constructivist teaching activities, the process of knowledge construction is happening to teachers simultaneously, and teachers must change their knowledge and teaching methods to adapt to students' learning as the situation changes. In this process, there is an equal and interactive cooperative relationship between teachers and students.

This theory has been adopted at all walks of the society, especially in education. Teachers are increasingly taking students into consideration and tailoring to their needs. Teachers are more like partners, who make a joint effort with students to learn skills 
better. To shorten the cost of learning, these facilitators are teaching, as well as learning. While exploring the ways to motivate their students, they are learning what exact help to offer and how to do so.

\subsection{The four roles that students have higher expectations for teachers are participant, resource provider, organizer, and mentor, followed by the assessor, and the lowest is the manager.}

Not only do teachers play an important role in inspiring students' interest in learning, but they are also organizers for cultivating students' learning abilities. They are essential to stimulate students' learning and make students' needs of learning knowledge and skills come true in the natural environment [7]. In terms of students' academic performance, teachers' leadership style has an emotional influence on that. Compared with authoritative and laissez-faire teachers, democratic teachers' leadership style is positively correlated with adolescents' positive academic [8], which can be described as a classroom with freedom, equality, and justice [9][10]. This teaching pattern likely embodies specific teachers' roles, likewise participant, resource provider, organizer, and mentor. These roles are within students' expectations. To some extent, students' interest in learning and motivation will be improved if they favor the teachers in that class [11].

At the same time, loving teachers will affect students' self-efficacy and the expected value of learning, beneficial to students' internal driving force for success [12]. Therefore, teachers in modern society should focus on these transformations because of the increasing equality of communication between teachers and students [13]. However, among the roles that teachers play in class, the functions of "controller" and "assessor" are better, while the parts of "organizer," "prompter," "participant," and "consultant" are not ideal [14].

\subsection{Teachers may Transfer their Roles Flexible Faced with Different Students and Various Tasks.}

Various tasks are often carried out by single teacher, while many roles are critical to the development of each student, a frequent transformation is of the essence. According to multiple tasks, students' expectation for teachers' roles changes over time [15]. In one course, teachers are likely to play different positions over that period. No matter how many roles they will take on, they need to transfer fluently. Otherwise, certain roles of the teachers may not be played. Take flip classroom as an example; it demands teachers to switch their positions at pace with the class segment rather than sticking to one role [16].
Individualized Education is also a criterion when it comes to the transformation of teachers' roles. Industrial Education is a uniform education. Education does not regard students as people with their characteristics but assumes that they are the same individuals, which comes at the high cost of suppressing or even sacrificing students' personality development [17]. This explains the rightful existence of tutorial instruction, which means teachers have different plans for each student. Moreover, there is a traditional Chinese saying centers around the idea of teaching students in accordance of their aptitude. It is an idea pedagogy rooted in traditional Chinese teaching, which could help teachers strive to treat students as individuals and to help each one to achieve their full potential. This ideology is overlapping with the Zone of Proximal Development (ZPD) by Lev Vygotsky [6]. It demonstrates the globalization of education and significance of changing different roles to motivate students in learning based on various social context.

\section{THE DIVERSIFIED ROLES OF TEACHERS SHOULD BE ADJUSTED APPROPRIATELY, AND THEIR TEACHING SHOULD RUN THROUGH A HOLISTIC APPROACH}

Teachers understand students' feedback in the teaching process and make teaching changes according to the input. Teachers need to constantly reflect on their teaching plan in the teaching process to optimize the teaching plan and better adapt to the level of students.

\subsection{To achieve the ideal teaching quality, teachers work hard to understand students fully and communicate with them in different ways outside of the Class.}

Teachers could communicate with students after Class to maximize class efficiency. The teaching time in the classroom is not long and valid enough for teachers to fully understand the students. To be more specific, the rapport between students and the teachers is not strong enough and the half-baked. Thus, the focus of Education should be narrowed down to cultivating and balancing all dimensions of each individual. Once the awareness of the interconnectedness of the teachers and the students is established, teachers could learn more about students' characteristics to promote their motivation of knowing better. During this process, the teachers are also changing their roles concerning students' ZPD. 


\subsubsection{Teachers connect with students through after-class communication, understand the uniqueness of each student.}

As a teacher, if you want students to develop in an all-around way and grow up healthily, you must first understand students' personalities and use different teaching methods to treat them. The teacher needs to know the character of the students after Class. Each student has various personality characteristics, so teachers need to understand the personality of all students so that students can play their role in Class and experience the fun of learning in Class. In the process of communicating with students, teachers need to have an equal dialogue with students. In the communication process, to truly understand students' personalities, teachers need to establish contact with students and communicate with students' parents to understand some educational ideas of students' parents to help understand students' personalities. After Class, teachers need to fully understand students' learning motivation and the factors that motivate or inhibit learning behind their motivation. Different family backgrounds and social environments have created students with different personalities. Teachers should analyze students' personalities and take appropriate methods to guide them. In understanding students' character, teachers should be patient and not judge students and help students learn to the greatest extent based on understanding students [18].

\subsubsection{After teachers understand students, they need to perfect and shape students' character}

Teachers' shaping of students' character is mainly through the example image in Class, the teachers' personalities after Class, and the relationship between teachers and students. Students learn knowledge in Class under the guidance of teachers. In this process, the transmission of knowledge and the core of knowledge are mediated by teachers. Students understand and absorb knowledge through the teacher's explanation. In this process, teachers need to maintain a cautious attitude and a responsible attitude towards students because students' understanding of knowledge mostly depends on the teacher's explanation and transmission. Therefore, in the whole learning process, teachers can constantly transmit the awareness of autonomous learning to students to form a more comprehensive and unique knowledge system. After Class, teachers need to have a sound personality, noble sentiment, professional ethics, and a positive image. In front of students, teachers need to play a leading role because students sometimes imitate teachers, and teachers need to restrain themselves at all times. The relationship between teachers and students is also an essential part of shaping students' character. Good teacher-student relationships can promote students' enthusiasm for learning and cultivate students' positive qualities [19].

\subsection{Teachers get the honest evaluation of teaching after Class to guide the shaping of teachers' multiple roles}

To Truly Optimize the Teaching Effect, Teachers need to Obtain Students' Real Teaching Feedback after Class, Seriously Think about the Optimization Scheme, Take Students as the Center, and Help Students Make Use of Classroom Learning Knowledge to the Greatest Extent.

\subsubsection{Real teaching evaluation improves the feedback of the students and the Class}

After Class, teachers need to get students' feedback on the classroom, and teachers themselves need to summarize the course effect. Course feedback can be carried out in various ways, such as simple questionnaires or simple communication with students in multiple grades to obtain information. The conclusion involves many aspects, including teaching equipment, teaching scheme, teacher-student connection effect, teaching improvement scheme, the overall feeling of teaching students, and individual students' unique situations. In this process, students should listen to their most real ideas and express their understanding of the course, what they like and don't like about the course. Teachers should maintain an equal attitude in the process of seeking feedback from students. Only in this way can they obtain honest and effective information feedback and optimize the curriculum.

\subsubsection{Teachers are improving their teaching programs in many ways. However, through feedback and conclusion, teachers should have a new understanding of their teaching plan.}

According to these two aspects, teachers need to deepen and improve their teaching programs. Through listening to the feedback, teachers could improve the teaching plan according to the overall ZPD of the students and select opinions that are most conducive to the improvement of the Class. Although in enhancing the teaching program, the overall improvement of the Class needs most of the time, the exceptional cases of individual students cannot be ignored. For example, for students with poor economic conditions or physical disabilities, teachers need to pay special attention to help them integrate into the Class, study with other students and pay attention to their physical and mental development. In addition to changes in teaching programs, teachers also need to change the facilities, such as multimedia and computers. Now is the information technology era. Teachers need to keep up 
with the pace of the times and use the latest teaching technology to help students adapt to social development [20].

\section{STRONG RAPPORT BETWEEN TEACHERS AND STUDENTS: EMOTIONAL SCAFFOLDING}

Teachers play a significant role throughout their students' lives, and it has been reviewed that students need guidance from the teachers both in Class or after Class. Meanwhile, it is helpful and practical for teachers to build strategies to meet students' emotional needs on distinctive occasions in combination with the actual situation.

\subsection{The use of 'emotional scaffolding' in Class}

It is common for teachers to use emotional Scaffolding in Class to stimulate students' learning motivation. Dynamic Scaffolding is scaffolding constructed by teachers using an analogy, visual representation, and storytelling to enhance communication with the students. For instance, teachers implement this method to connect the specific teaching content with accompany with the emotional world of the students. Thus, to stimulate students' particular emotional response to subject knowledge, and finally, help students have a positive and dynamic learning experience. [21]

As teachers prepare their lessons, they might consider the difficulties the tasks bring to the students. For example, if the content is too changing, it may arouse negative emotions in the students; it is the same with the content being oversimplified; students may feel boring during the lecture. When encountering situations like that, implementing 'emotional scaffolding' for some parts of the lesson is an effective way of teaching, which helps guide students out of their habitual thinking mode and promotes them to establish new emotional connections with this part of the content. Thus, dynamic Scaffolding is also a considerable option to stimulate students' learning motivation.

\subsection{Students' emotional needs from teachers after Class}

Besides paying attention to students' emotional needs in Class, students expect their teachers to understand and take care of their emotional needs after Class. To be more specific, teachers showing mutual respect to students and providing various emotional needs according to their different ZPD levels could significantly change the student's internal motivation to learn.

In addition to this, the established thought of the dignity of teachers in the relationship between teachers and students emphasizes the importance for students to respect their teachers. [22] However, it is only working with the mutual respect that teachers offer to their students. To be more precise, students are independent and sometimes could have unexpected insights on things. If teachers could recognize the highlights of their students with sincerity, students would have a better understanding of mutual respect and the benefits it brings.

Further, mutual understanding and respect offered by the teacher need to align with the ZPD of their students. Teachers should give the corresponding reference to students at different levels and have an unbiased attitude towards the students' personalities. Generally, the "advanced level" students' demand for respect is the complete trust of teachers to display their talents better; The students in the "middle level" account for the majority, but they are easily ignored most of the time. Their demand for respect is the concern and love of teachers. The warmth teachers can give the students would reassure them that they have not been forgotten; The demand of "backward level" students to respect is the teacher's political trust and personal respect for them, equal treatment rather than discrimination. [23]

The comparative research between China and Britain a decade ago remains relevant to today's education, especially with studying the relationship between the students and the teachers. Below is short conversation analysis (CA); apparently, the "backward level" student was discouraged and even lost confidence at first. The CA recognizes that the teacher does not walk away from the troubled student; instead, he communicates with the student with respect and understanding. After the conversation, the student could easily sense the respect and care from the teacher. The example illustrates a successful use of emotional Scaffolding, which could promote the development of students' learning competency and autonomy.

TEA indicates the teacher

STU indicating the student

TEA: You're very smart. (0.2) do you know that? ((look at the student and smile))

STU: $\mathrm{Me}^{\wedge}$ ?

TEA: Yeah, of course`?(.hh) You're sma::rt.(0.5)

STU: ((Put right hand on left arm and look at the teacher))

TEA: You have (0.2) to learn::: be smart:ter.

STU: ((nod)) ((teacher put his hand down slowly))

TEA: You never know:: what you will do in the future. (0.3) You might fell regret (.hh) I should have learn::ed (0.7) har::d.

STU: Yeah,((nod))

TEA: So (0.5) are you willing to change,

STU: Yeah:. 
TEA: Be more:: focused.

STU: $\quad$ Try my best.((look at the teacher))

TEA: Try your be: st.

Caring students could be seen in various forms, with time and giving different forms of care centers around the students. Each student would encounter develop academically but in multiple formats. Teachers are becoming significant in their students' eyes by providing students with different forms of attention based on their other characteristics. For example, for those extroverted students, teachers can communicate with them directly without beating around the bush; on the contrary, for those introverted students, teachers need to measure a different approach of communication and allow the trickle of feelings to penetrate slowly. [23]

Moreover, timing is essential for teachers and when to express their concerns to students. For instance, for students who have just graduated from university and their direction of job hunting remains unclear, teachers might organize help sessions delivered via the internet or face to face. However, for students who have just entered the university and feel confused about their academic ability, teachers could hold freshman guidance sessions with their years of experience combined with the student's ZPD. Thus, such measures could make the students feel the attention given by the teachers, and their confidence in overcoming the challenges becomes heightened, which could stimulate their internal motivation of learning.

\subsection{Reciprocity between teachers and the students}

In a harmonious, equal, and positive teacher-student relationship, teachers establish authentic examples for students to learn from and learn from students and grow together with them. The rapport between teachers and students is conducive to the better development of both sides, and many would prefer this as the interchange between teachers and the students.

Teachers are expected to set real-life examples for students because students' emotions will be subconsciously affected by teachers. 'Rosenthal Effect 'proves that students' feelings and attitudes can be inadvertently affected by teachers to varying degrees, and they tend to accept the influence and the hint from the teachers that they like, admire, and trust. [24] Therefore, teachers should set good. Thus, students at any time, their positive attitude will inadvertently affect students. The positive emotion of teachers will also improve students' learning, motivation, and enthusiasm. Also, this positive emotion will become one of the fundamental driving forces for students to make progress.

Then, teachers are no longer the authority of the entire learning process, they are still learning, and the great source is coming from their students. With this being said, teachers are not the controllers of the classroom for the entire lecture; instead. Therefore, the dominant position of students in Class has been emphasized. On the one hand, students are just younger than teachers in age; their knowledge capacity is not as profound as their teachers. However, each student would carry on their insights to the classroom once the teacher discovers their strengths, self-esteem, and ability to learn become firm. On the other hand, teachers are expected to be good listeners to accompany the needs and opinions of the students. Thus, self-reflections from the teachers and students together retain the advantages accepted by students and actively improve the $\mathrm{d}$ disadvantages. In such an equal relationship with students, both teachers and students can grow and promote themselves, which is also conducive to the future development of both parties.

\section{CONCLUSION}

To conclude the conceptual themes investigated in this short review article, the literature review and the discussion are developed based on the diversified roles of teachers and how this phenomenon promotes the goal of stimulating students' internal motivation of learning. The teacher-student relationship has always been considered as significant in Education besides the academic performances of the students. How teachers change and adopt different roles for students through a holistic aspect is essential in Education. According to Todorescu, Popescu-Mitroi, and Greculescu, students expect their teachers to perform the roles of the creator of learning situations and consultant and be a model of behavior [25]. Many research and case studies have revealed that the ultimate goal is to stimulate students' internal motivation on the diversified practice of teachers' roles. These processes require time and energy from the teacher, and it is often tricky in a particular social context, especially those with a larger population of students. However, as the article reveals, there is traditional teaching pedagogy similar to the philosophies of ZDP, which is to teach according to each student's potential of learning.

Therefore, this short review article discusses different theoretical interpretations of teachers' comprehensive multi-role literacy, which prompt teachers to change their roles flexibly with varying students inside and outside the classroom. Meanwhile, teachers further deepen their relationship with students using emotional Scaffolding, and others achieve the dynamism of teaching and learning. To sum up, this short review article is organized with authentic classroom dialogues, case studies, and other related literature to measure the significance of the diversified roles of teachers to catalyze the internal motivation of students' learning. 


\section{REFERENCES}

[1] DEWEY, J. (1997) Democracy and Education: an introduction to philosophy of education (New York, Touchstone/Simon \& Schuster) [Original work published 1933].

[2] Rogers C R . On Becoming A Person A Therapist's View of Psychotherapy: personne houghton mifflin company, 1961.

[3] Rogers, C.R. (1942). Counseling \& psychotherapy: Newer concepts in practice. Boston, MA: Houghton Mifflin.

[4] Maslow, A. H. (1973). The farther reaches of human nature. VIKING PRESS.

[5] Piaget, J., \& Inhelder Bärbel. (1969). The psychology of the child: 8 . print.

[6] Vygotskiǐ L. S., Vygotsky, L. S., \& Cole, M. (1978). Mind in society: The development of Higher Psychological Processes. Harvard University Press.

[7] Zhang Yanjun, Pei Wenjie, Liwen Wu. Research on the influence of gender, grade and favorite teacher on students' STEM learning attitude Based on the investigation of six middle schools in Zhejiang Province $[\mathrm{J}]$. Open Education Research, 2020,26(06):100-109.

[8] Lu Guizhi, Ren Xiuhua. Research on the Influence of Teachers' Leadership Style on Junior High School Students' Academic Emotion [J]. Educational Theory and Practice, 2010,30(02):4143.

[9] GREENE, M. (1988) A Dialectic of Freedom (New York, Teachers College Press).

[10] KELLY, T. E. (1994) Democratic empowerment and secondary teacher education, in: J. M. NOVAK (Ed.) Democratic Teacher Education: programs, process, problems, and prospects (Albany, NY, SUNY Press).

[11] Dou Wenyu. Research on Teachers' Classroom Role in Senior High School English Teaching [D]. Tianjin Normal University, 2012.

[12] Bong , M . , \& Skaalvik , E. M . (2003) . Academic self-concept and self-efficacy: How different are they really [J] . Educational psychology review, 15( 1): $1-40$.

[13] Song Guangwen, Miao Hongxia. The transformation of teachers' role in the network age [J]. Educational Research, 2001(08):40-44.
[14] Li Xiaohong. Research on the classroom role transformation of junior high school English teachers under the new curriculum background [D]. East China Normal University, 2007.

[15] Kelly R. Mazzer \& Debra J. Rickwood (2015) Teachers' role breadth and perceived efficacy in supporting student mental health, Advances in School Mental Health Promotion, 8:1, 29-41, DOI: 10.1080/1754730X.2014.978119

[16] Chen Yan. turning over the misunderstanding, transformation and realization path of English teachers' role in classroom [J]. educational theory and practice, 2021,41(12):39-42.

[17] Huo Liyan. the transformation of education and the transformation of teachers' role [J]. educational research, 2001(03):70-71.

[18] Li Licheng, Master students' personality characteristics and promote students' healthy growth [J]. Basic education reference, 2014 (06) :71-72

[19] Li kun, On the influence of teachers' personality on the formation of students' personality [J]. Journal of Cangzhou Normal University, 2008, 24 (04) : 119-120

[20] Hu Linli, On the optimization of school physical education teaching methods [J]. Journal of Cangzhou Normal University, 2008, 24 ( 04 ) : 119, DOI: 10.3969/j.issn.10084762.2008.04.057

[21] Xiaobin Zhu\&Ling Xu (2012) , The researches and application of emotional Scaffolding in American teaching practice, Studies in Foreign Education, 39 (11) , 75,

[22] Shuyi Zhu (2017) , On establishing a new relationship between teachers and students, Human Resource Management, 2017 (11) , 121, doi: 10.3969/j.issn.1673-8209.2017.11.101

[23] Lihong Zhang (2003) , The art of "emotional investment" in college students' work under the new situation, Journal Of Hebei University (Philosophy And Social Science)28 (3) , 137138, doi: 10.3969/j.issn.1000-6378.2003.03.033

[24] Dan Liu (2017), The value and cultivation of teachers' positive emotion to the student and teacher development, Teacher Education Research, 29 (06) , 25, 
[25] Todorescu, L.-L., Popescu-Mitroi, M.-M., \& Greculescu, A. (2015). Changes in students' expectations from teachers' roles in Secondary Education. Procedia - Social and Behavioral Sciences, 197, 190-196. https://doi.org/10.1016/j.sbspro.2015.07.122 